\title{
PURULENT MENINGITIS IN THE NEONATAL PERIOD
}

\author{
BY \\ J. S. YU and A. GRAUAUG \\ From the Institute of Child Health, Royal Alexandra Hospital for Children, Sydney, N.S.W., Australia
}

(RECEIVED FOR PUBLICATION DECEMBER 31, 1962)

Purulent meningitis remains a significant cause of death in the neonatal period.

In this study a group of newborn infants with meningitis has been reviewed with particular reference to the initial findings in the cerebrospinal fluid, the incidence of organisms at different ages within this period and the use of corticosteroids. The subsequent progress of these babies is described.

\section{Subjects and Methods}

Forty-seven babies with neonatal meningitis treated at the Royal Alexandra Hospital for Children over the eight and a half years from July 1953 to December 1961 are reviewed. Eighteen babies in whom the meningitis was a complication of myelomeningocele have been excluded from the series.

Patients have been included if there was evidence at autopsy of pyogenic meningitis or if examination of the cerebrospinal fluid showed a polymorph pleocytosis and a raised protein level, whether or not a causative organism was isolated.

Nineteen of the patients survived the acute illness. One of these survivors died of an unrelated illness within 12 months of his episode of meningitis. Of the remaining 18 patients, 17 were seen by the authors. One could not be traced.

Each child was assessed after an interview with the parents. When advisable, the child was also seen separately. Physical examination, electroencephalography and audiometry were performed as well as psychological and psychometric testing. Where indicated, an ophthalmological consultation was obtained.

The oldest child in this series was $8 \frac{1}{2}$ years and the youngest 9 months.

\section{Results}

Clinical Findings. The clinical picture of neonatal meningitis is both diverse and non-specific. The most frequently encountered early symptoms are an abnormal temperature, a change in feeding habits, abnormal behaviour including irritability and lethargy, and respiratory distress (see Table 1). Convulsions and a bulging fontanelle were seen late in the disease.
Of the babies, $20 \%$ had a subnormal temperature on admission, and this was more common in the fatal cases. The majority of deaths in the group with a subnormal temperature occurred within 24 hours of admission.

The delay in diagnosis is difficult to assess in a retrospective study, but was probably about one to two days.

Eight babies were premature and 17 others had significant obstetric abnormalities. These included abnormal presentations, prolonged labour, difficult forceps delivery and premature rupture of the membranes.

Laboratory Findings. By definition only those cases with cerebrospinal fluid polymorphonuclear pleocytosis have been included. The lowest count was 75 polymorphs per c.mm.; this specimen subsequently grew Proteus vulgaris. Of the remaining polymorph counts $75 \%$ were in excess of 1,000 cells per c.mm. No relation between cell counts and the severity of the illness could be demonstrated.

The cerebrospinal fluid protein content was estimated using a turbidimetric method. The protein content was estimated in 36 specimens taken at initial lumbar puncture. Of the 15 survivors examined, seven had a cerebrospinal fluid protein content less than $300 \mathrm{mg}$. per $100 \mathrm{ml}$. and eight exceeded $300 \mathrm{mg}$. per $100 \mathrm{ml}$. Of those that died,

TABLE 1

PRESENTING SYMPTOMS

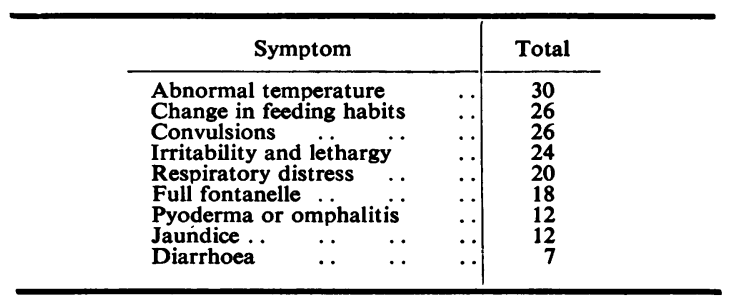


TABLE 2

CAUSATIVE ORGANISMS

\begin{tabular}{|c|c|c|c|c|c|c|c|c|c|}
\hline \multicolumn{4}{|l|}{ Organisms } & Total & $\begin{array}{l}\text { Age of Onset } \\
0 \text {-14 days } \\
\text { (No.) }\end{array}$ & $\begin{array}{c}\text { Age of Onset } \\
15-28 \text { days } \\
\text { (No.) }\end{array}$ & $\begin{array}{c}\text { Percentage } \\
\text { of } \\
\text { Total }\end{array}$ & Deaths & Survivors \\
\hline $\begin{array}{l}\text { Esch. coli .. } \\
\text { Paracolon .. } \\
\text { Pseudomonas } \\
\text { Proteus .. } \\
\text { Strep. faecalis } \quad \ldots \\
\text { Staph. aureus .. } \\
\text { Strep. haemolyticus } \\
\text { Pneumococcus } \\
\text { Haemophilus influenzae } \\
\text { Unidentified } \\
\text { Total enteric organisms } \\
\text { Total .. }\end{array}$ & $\begin{array}{l}\cdots \\
\cdots \\
\cdots \\
\cdots \\
\cdots \\
\cdots \\
\cdots \\
\cdots \\
\cdots\end{array}$ & $\begin{array}{l}\cdots \\
\cdots \\
\cdots \\
\cdots \\
\cdots \\
\cdots \\
\cdots \\
\cdots \\
\cdots\end{array}$ & $\begin{array}{l}\cdots \\
\cdots \\
\cdots \\
\cdots \\
\cdots \\
\cdots \\
\cdots \\
\cdots \\
\cdots\end{array}$ & $\begin{array}{r}17 \\
7 \\
3 \\
2 \\
1 \\
3 \\
2 \\
3 \\
1 \\
8 \\
30 \\
47\end{array}$ & $\begin{array}{r}14 \\
5 \\
1 \\
2 \\
1 \\
0 \\
0 \\
1 \\
1 \\
1 \\
23 \\
26\end{array}$ & $\begin{array}{r}3 \\
2 \\
2 \\
0 \\
0 \\
3 \\
2 \\
2 \\
0 \\
7 \\
7 \\
21\end{array}$ & $\begin{array}{r}36 \cdot 2 \\
14 \cdot 9 \\
6 \cdot 4 \\
4 \cdot 3 \\
2 \cdot 1 \\
6 \cdot 4 \\
4 \cdot 3 \\
6 \cdot 4 \\
2 \cdot 1 \\
17 \cdot 0 \\
63 \cdot 8 \\
100 \cdot 0\end{array}$ & $\begin{array}{r}11 \\
4 \\
3 \\
1 \\
1 \\
2 \\
2 \\
2 \\
2 \\
0 \\
2 \\
20 \\
28\end{array}$ & $\begin{array}{r}6 \\
3 \\
0 \\
1 \\
0 \\
1 \\
0 \\
1 \\
1 \\
6 \\
\mathbf{6} \\
10\end{array}$ \\
\hline
\end{tabular}

two had a protein less than $300 \mathrm{mg}$. per $100 \mathrm{ml}$., while 19 exceeded this figure. The group of survivors have significantly lower initial cerebrospinal fluid protein levels $(\mathrm{p}<0 \cdot 05)$.

The complications of subdural effusions and hydrocephaly occurred in $29 \%$ of the survivors with protein levels less than $300 \mathrm{mg}$. per $100 \mathrm{ml}$. and in $88 \%$ of the survivors with protein levels greater than $300 \mathrm{mg}$. per $100 \mathrm{ml}$. The numbers though small are suggestive of some prognostic value in protein levels.

In the four cases in whom the cerebrospinal fluid was not examined, the diagnosis was made at autopsy.

The Causative Organism. Enteric organisms accounted for $64 \%$ of cases (Table 2). If, however, the first 28 days of life are divided into two equal periods, then enteric organisms account for $81 \%$ of cases occurring in the first 14-day period, but only $33 \%$ in the second 14-day period. Eight infections due to Gram-positive cocci were found. Seven of these occurred in the second 14-day period.

Esch. coli was the most commonly found organism, occurring in 17 cases $(37 \%)$, with organisms of the paracolon group in seven cases $(14.9 \%)$. More detailed identification was not attempted within these groups. Gram-positive cocci accounted for $10 \%$ of cases. There were three cases caused by pyogenic staphylococci, three by pneumococci, and two by the haemolytic streptococcus. A further two cases were due to Proteus and three to Pseudomonas. Haemophilus influenzae remains a rare cause with only one case being found.

In eight of the 47 cases no causative organism was identified. Three infants who had been partially treated with broad spectrum antibiotics before admission had a polymorph pleocytosis in excess of 1,000 cells per c.mm., and protein levels greater than $300 \mathrm{mg} . / 100 \mathrm{ml}$. In two of these, Gram- negative rods were seen on a direct smear of the spinal fluid, but subsequent culture was sterile. The cerebrospinal fluid from two babies was examined elsewhere and the culture results are not obtainable. The remaining three had a significant polymorph pleocytosis and elevated protein levels; however, direct smear and culture failed to demonstrate an organism.

The overall mortality was significantly better when no organisms were found.

Treatment and Early Results. The babies included in this study were admitted in approximately equal numbers under the care of one of the five medical units in the Royal Alexandra Hospital for Children. When the diagnosis was made treatment with antimicrobials was given by the intravenous route. Chloramphenicol was administered to 40 babies, streptomycin to 37 , sulphadimidine to 32 and penicillin to 13. A combination of chloramphenicol, streptomycin and sulphadimidine was given to 32 and only in the later period of this study was the standard combination employed.

Sensitivity results on 26 enteric organisms isolated showed streptomycin to be effective in $100 \%$, chloramphenicol in $80 \%$, tetracycline in $73 \%$, and sulphadimidine in $31 \%$. Tetracyclines were not commonly employed.

Corticosteroids were given to 22 babies. The administration of steroids was advocated by the physicians of two of the medical teams and all cases admitted under their care received steroids on diagnosis.

The overall mortality in this study was $60 \%$. The mortality rate of the 22 babies treated with corticosteroids was $41 \%$, while of the 25 who did not receive corticosteroids $75 \%$ died. In the latter group three babies did not receive appropriate or adequately administered antimicrobials. Two were given penicillin alone and the remaining baby oral chloram- 
phenicol. If these three babies are omitted from this group then the uncorrected $\chi^{2}$ is $4 \cdot 54$ for one degree of freedom and thus the result is significant at the $5 \%$ level. Many observers would use the corrected $\chi^{2}$ which is 3.34 and not significant at the $5 \%$ level. This test is known to be very conservative (Table 3).

The small numbers make any analysis of mortality rates and causative organisms unreliable. The better survival in the group where no bacteriological identification was made ( $25 \%$ mortality) is noteworthy.

Late Results. The complication rate of the surviving 19 babies was high $(63 \%)$. Seven who made uncomplicated recoveries were quite normal when seen. Of the remaining 10 babies seen, four had made complete recoveries.

One boy aged 6 years was physically normal, but presented with considerable behaviour problems. His developmental patterns were retarded compared with his siblings, though his electroencephalogram tracing was normal. Another boy aged 4 years was found to have severe hearing loss in one ear, but no other abnormalities. He had not received streptomycin, and his development, except for delay in commencing to speak, seemed to be progressing normally. Subdural effusions were detected during the convalescence of two babies, one with an Esch. coli infection, and the other with $H$. influenzae. The effusions resolved after tapping and subsequent progress has been normal.

Hydrocephaly developed in eight cases, four had Esch. coli infection, one pneumococcus, and in three no organisms were isolated. In five of the eight babies, hydrocephaly stabilized and did not require surgery. Two of these were normal at review and had head circumferences within the normal range; one was severely epileptic and retarded, one died of an unrelated illness, and the last could not be traced. The remaining three babies required surgery, and of these two had lumbar arachnoid shunts for communicating hydrocephaly and were normal when seen. One baby with non-communicating hydrocephaly was treated with a ventriculo-caval shunt. This has required revision once. He is now $2 \frac{1}{2}$ years old and appears normal. An electroencephalogram, however, shows a marked posterior occipital abnormality on the left side. He is too young to test his visual fields adequately, but there does not seem to be any gross impairment.

The results of psychometric testing are difficult to correlate because of the different techniques required over this considerable age range. In children under 3 years, the Ruth Griffiths Scale was used with the Vineland Social Maturity Scale. In
TABLE 3

\begin{tabular}{cc|c|c|c}
\hline Results & $\begin{array}{c}\text { Treated With } \\
\text { Corticosteroids }\end{array}$ & $\begin{array}{c}\text { Not Treated With } \\
\text { Corticosteroids }\end{array}$ & Total \\
\cline { 1 - 2 } $\begin{array}{ccc}\text { Recovered } \\
\text { Died } . .\end{array}$ & $\ldots$ & 13 & 6 & 19 \\
\hline Total &.. & 9 & 16 & 25 \\
\hline
\end{tabular}

$\mathrm{n}=1 ; \chi^{2}=4 \cdot 45 ; \mathrm{p}<0 \cdot 05$.

older children a Binet ( $\mathrm{L}$ scale) and the Vineland Scale were used. All children were assessed with Mary Sheridan's Developmental Patterns. Electroencephalograms were normal in all the children except two. In one child, who was severely epileptic and retarded, a left temporal focus was present; and in another, an apparently asymptomatic left occipital anomaly: this boy did not appear to have any visual defects. A total or very severe hearing loss was found in the left ear of one boy aged $3 \frac{1}{2}$ years. On examination no abnormality was found and his electroencephalogram was normal. Audiometric studies on all the other children were normal.

\section{Discussion}

Pathogenesis. The pathogenesis of neonatal meningitis has been well described by Groover, Sutherland and Landing (1961). It appears that most, if not all, of these babies have a preceding bacteraemic phase. Blood cultures were performed in only two babies of this series, and in both instances grew identical organisms from the blood and cerebrospinal fluid. Ziai and Haggerty (1958) found 52 positive blood cultures in the 71 cases examined. In some babies there was a profound constitutional upset in the presence of minor cerebrospinal fluid changes and, had it been sought, evidence of bacteraemia might have been found. Blood cultures seem to be an advisable investigation in all future cases.

A majority of the babies in this study were males, a finding common to all reported series. An abnormal obstetric history is certainly common in both male and female babies studied here. Prematurity is the outstanding anomaly, occurring in $17 \%$. Ziai and Haggerty (1958) report a $30 \%$ incidence of prematurity while others report greater percentages (Craig, 1936; Groover et al., 1961). Other factors encountered include abnormal presentations, prolonged labour, difficult forceps delivery and premature rupture of the membranes.

This study has shown a striking pattern in the incidence of the enteric organisms. In the first 
14 days of life $81 \%$ of cases were due to enteric organisms as compared with $33 \%$ in the second 14-day period. The great majority $(89.5 \%)$ of infections due to Gram-positive cocci occurred in this second 14-day period. This pattern is similar to the findings of Ziai and Haggerty (1958).

The flora of the birth canal and its environment must provide a rich source of potentially infective enteric organisms, though a more important factor may be the status of antibody levels in the newborn. The antibacterial antibodies against Esch. coli $\mathrm{H}$ and $\mathrm{O}$ diffuse poorly across the placental membrane (Vahlquist, 1960) in contrast to those of most other bacterial pathogens, and are present in very low or zero levels in the foetus. Yeivin, Salzberger and Olitzki (1956) found that antibody levels in the newborn were lower than maternal levels using Esch. coli serological types 055 and 0111 . It should, however, be noted that enteropathic Esch. coli were not identified in seven cases of Esch. coli meningitis typed by Dupont and Thamdrup (1956). There is widespread colonization of the gut in the first few days of life by Esch. coli, and there is some evidence to suggest increased mucosal permeability to microorganisms (Vahlquist, 1960). The meninges also show increased permeability (Otila, 1948).

These factors probably contribute largely to the prevalence of severe invasions with Gram-negative rods in the early neonatal period.

Vahlquist (1960) states that gamma globulins and antibodies do not make their appearance in foetal blood in measurable quantities till mid-pregnancy, reaching their peak at the 8th-9th month. This depleted level of passive antibodies in the foetus is again consistent with the high incidence of prematurity in this disease. Eight babies in this series were premature.

The decay of these passive gamma globulins is along a simple exponential curve and their half-life is of the order of four weeks (Orlandini, SassKortsak and Ebbs, 1955). The antibodies to the Gram-positive cocci pass the placental membrane with ease, but little is known of their fate. The incidence of infections due to Gram-positive cocci appears to rise with the expected fall in these gamma globulin levels. The skin seems to be the chief portal of entry for Gram-positive organisms.

Clinical Findings. The symptoms and signs of meningitis as it occurs in the newborn period are non-specific and a full fontanelle and convulsions represent a late picture.

In six of the 47 babies the diagnosis was unsuspected and lumbar puncture was not performed. These all presented with feeding difficulties and respiratory distress. Two babies were febrile and the remaining four had normal or subnormal temperatures. This stresses the need for early cerebrospinal fluid examination in undiagnosed neonatal disease.

Treatment. The most important factor in effective treatment of neonatal meningitis is early recognition.

(a) Antibiotic Therapy. The group of babies contains too many variables for a reliable assessment of individual antibiotic efficacy. While awaiting sensitivity tests some standard antimicrobial régime must be given. The number of agents required for safe effective treatment is as difficult to determine as the choice. In this series two or three agents have been generally used in an effort to cover the spectrum of infective agents with inhibitory cerebrospinal fluid levels. There is no evidence to suggest or deny that this is optimal treatment.

Sensitivity tests show the enteric organisms were all sensitive to streptomycin and $80 \%$ sensitive to chloramphenicol. Their combination provides a reliable broad spectrum cover. The dosage of streptomycin used was $50 \mathrm{mg}$. per $\mathrm{kg}$. per day for the first two days then $25 \mathrm{mg}$. per $\mathrm{kg}$. Chloramphenicol was given in a dosage of $25 \mathrm{mg}$. per $\mathrm{kg}$. per day in the later part of the study, though larger and possibly toxic doses were used earlier and may have caused the deaths of two babies. Sulphadimidine was sometimes added.

Five babies received intrathecal streptomycin, but no conclusions can be drawn; three babies died and two survived. Dyggve (1962) advocates this treatment, but his numbers are similarly small and inconclusive. If given in an appropriate dose, it may prove to be a valuable adjunct. A dose of $20 \mathrm{mg}$. given once or twice has been used.

The Gram-positive cocci showed their usual sensitiveness with two of the three staphylococci isolated being resistant to penicillin. Before positive identification, these all received chloramphenicol, penicillin and sulphadimidine. If a staphylococcal infection seems likely, there is little doubt that methicillin should replace penicillin until sensitivity tests are available. If the baby were admitted from a maternity hospital, then the likelihood of a resistant staphylococcus is increased.

(b) Corticosteroids. Corticosteroids were used in approximately half the babies of this series. Whether steroids were given or not depended on which medical unit cared for the baby. The survival rate in the steroid group was $59 \%$ as compared with $25 \%$ in those who did not receive steroids. These 
figures are strongly suggestive $(p=0.05)$ that this mode of therapy should be continued until further assessment can be made. Hydrocortisone was given intravenously, $75-100 \mathrm{mg}$. in divided doses for the first 24 hours then changed to oral prednisone. Provided adequate antimicrobial cover is given, corticosteroids should present no dangers. The mode of action of steroid has been and remains obscure.

Of the many actions cited by Tompsett (1961), the detoxifying effects of the corticosteroids seem most relevant to this situation. Much has been written about the endotoxin shock associated with the Gramnegative bacteraemias (Spink, 1960). Its mechanism is unknown and studies in human and experimental animals have failed to demonstrate adrenocortical failure even in the moribund. However, large doses of steroids in the initial acute period of such a bacteraemia facilitated the maintenance of blood pressure by hypertensive agents and had a profound effect in reducing toxicity in the usual clinical sense. A similar endotoxin action may be involved in these babies with meningitis. Anoxia at a renal or central site may explain the occasional baby who becomes oedematous with water and electrolyte disturbances.

Despite the improved survival figures, steroids did not seem to influence the development of those complications attributed to inflammatory changes. The occurrence of subdural effusion and hydrocephaly was the same in the treated and untreated groups, suggesting that steroids play their main role in the support and maintenance of the toxic baby in the acute phase.

(c) Other Supportive Measures. These include blood transfusions and gamma globulin. Human gamma globulin was not used in this group of patients, but if the status of antibodies is significant, as postulated, then its administration may prove helpful.

Prognosis. Ten years ago the outlook in neonatal meningitis was particularly gloomy and in this hospital Beveridge (1954) found a mortality rate of $100 \%$. Since then awareness of the disease has improved as have the techniques of antibiotic usage.

In this series, those babies with an initial cerebrospinal fluid protein level in excess of $300 \mathrm{mg}$. per $100 \mathrm{ml}$. had a higher morbidity and mortality rate. Those babies presenting with a subnormal temperature also did poorly and this may be an indication of endotoxin shock.

The overall mortality in this series $(60 \%)$ is com- parable with other reported studies (Watson, 1957; Ziai and Haggerty, 1958; Groover et al., 1961); however, in those babies treated with corticosteroids there was a $41 \%$ mortality. Of the 19 survivors, 11 have made a good recovery and now appear normal; five have some moderate disability such as behaviour problems, partial deafness and backward development, but should be able to lead a useful life; one is severely retarded and epileptic; one had died and another could not be traced.

It is difficult to assess the potential that these children possessed before their illness. Their present development is parallel to that of their siblings. In general these children score lower in those tests involving hearing and speech. All were subjected to audiometric testing and only one was found to be defective. A surprising feature was the good result obtained on those children who had suffered such complications as stabilized and corrected hydrocephaly.

\section{Summary and Conclusions}

Forty-seven infants with neonatal meningitis treated between July 1953 and December 1961 are reviewed and an assessment of the survivors made.

The clinical picture in this age period is diverse and non-specific with convulsions and bulging fontanelle as late manifestations. If there be any suspicion of meningitis then a lumbar puncture should be performed and this may provide the diagnosis and be a guide to therapy and prognosis.

Cerebrospinal fluid protein levels in excess of $300 \mathrm{mg}$. per $100 \mathrm{ml}$. were associated with a significantly higher mortality and complication rate.

In the first two weeks of life the enteric organisms cause the great majority of cases. Almost all the Gram-positive cocci occurred in the second twoweek period. The antibody levels of the newborn infant may contribute to this pattern. Esch. coli was the most common causative organism followed by the paracolon group, Proteus, Pseudomonas and the Gram-positive cocci. Most cases were probably associated with a bacteraemic phase and blood cultures are considered advisable.

The enteric organisms were usually sensitive to streptomycin and chloramphenicol. In addition sulphadimidine was frequently used. The combination of these three drugs is advocated. Until sensitivity tests were known infections due to Grampositive cocci were treated with chloramphenicol, penicillin and sulphadimidine. Approximately half the babies received corticosteroids in the acute phase and these had a significantly better survival rate $(59 \%)$ than the others $(25 \%)$. Antimicrobials and 
steroids were given intravenously during the first 24 hours of therapy.

There was an overall mortality rate of $60 \%$ with a lower rate of $41 \%$ in the group treated with steroids. These results suggest that steroids are of value and should be used in the acute phase. Seventeen survivors of the initial illness were seen and examined. Despite a high complication rate $(63 \%)$, the final recovery in 11 children was good. An encouraging number emerged from the complication of hydrocephaly and subdural effusions with only minor disabilities.

The single most important factor in prognosis is early diagnosis and any newborn infant with an unexplained illness should have a cerebrospinal fluid examination.

We have much pleasure in acknowledging the help and encouragement of Professor Thomas Stapleton. Our thanks are also due to Dr. Bryan Dowd and Professor John Beveridge for their advice during the prepara- tion of this paper, and to the Honorary Physicians of the Royal Alexandra Hospital for Children for allowing us to see their patients.

\section{REFERENCES}

Beveridge, J. (1954). Purulent meningitis in infancy and childhood. Med. J. Aust., 1, 932.

Craig, W. S. (1936). Meningitis in the newborn. Arch. Dis. Childh., 11, 171 .

Dupont, A. and Thamdrup, E. (1956). Neonatal meningitis. Dan. med. Bull., 3, 6 .

Dyggve, H. (1962). Prognosis in meningitis neonatorum. Acta paediat. (Uppsala), 51, 303.

Groover, R. V., Sutherland, J. M. and Landing, B. H. (1961). Purulent meningitis of newborn infants. New Engl. J. Med., 264, 1115

Orlandini, O., Sass-Kortsak, A. and Ebbs, J. H. (1955). Serum gamma globulin levels in normal infants. Pediatrics, 16, 575 .

Otila, E. (1948). Studies in cerebrospinal fluid in premature infants. Acta paediat. (Uppsala), 35, Suppl. 8, 3.

Spink, W. W. (1960). The pathogenesis and management of shock due to infection. Arch. intern. Med., 106, 433.

Tompsett, R. (1961). Steroids in infection. Postgrad. Med., 30, 3. Vahlquist, B. (1960). Neonatal immunity. A.M.A. Amer. J. Dis. Child., 99, 729.

Watson, D. G. (1957). Purulent neonatal meningitis. J. Pediat., 50, 353 .

Yeivin, R. Salzberger, M. and Olitzki, A. L. (1956). Development of antibodies to enteric pathogens; placental transfer of antibodies and development of immunity in childhood. Pediatrics, $18,19$.

Ziai, M. and Haggerty, R. J. (1958). Neonatal meningitis. New Engl.J. Med., 259, 314. 